\title{
IMPACT after 17 years: Lessons learned about successful networking
}

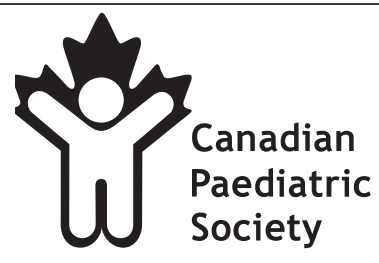

$T^{\text {he }}$

he Canadian Immunization Monitoring Program, ACTive (IMPACT) ranks as one of the Canadian Paediatric Society's (CPS) most innovative and productive activities (1); it recently marked its 17 th year of operation and logged its 18,000 th case report. I have had the privilege of being co-leader from the outset, first with Dr Ron Gold and then with Dr Scott Halperin. In January 2008, Dr Wendy Vaudry was elected to replace me in the co-leadership role and she, along with Scott Halperin, will ensure the project's continuing success. I will remain involved as the data centre chief. The role of project historian is also my reluctant burden, so I would like to make a few personal observations about IMPACT and the CPS's role in its success.

\section{HOW DID IMPACT COME ABOUT?}

The impetus for IMPACT was rooted in the growing public concern in the late 1980s about the safety of childhood vaccines, especially the pertussis vaccine and its alleged capacity to cause brain damage. The federal government's response was to establish an Immunization Division within Health Canada, led by Dr Philippe Duclos, with a mandate to better define vaccine safety. He improved the passive surveillance system for vaccine-related adverse events, but it failed to detect an increased risk of aseptic meningitis from a new mumpscontaining combination vaccine, which was used from 1986 until 1988. Attention was drawn to the problem by virologists at several children's hospitals across Canada. This shortcoming (and others) of the passive surveillance system prompted the Immunization Division to sponsor a workshop in Vancouver, British Columbia, in 1990, to consider additional options for improving vaccine safety surveillance. Attendees (including myself) recommended the creation of an active surveillance system based in children's hospitals across the country, as an additional 'finger on the pulse'. Health Canada subsequently asked the CPS to make a proposal for such a network.

\section{WHY WAS THE CPS THE HOST ORGANIZATION?}

The CPS was a smaller organization in 1990 than it is now, with limited resources apart from a visionary Executive Director in Dr Victor Marchessault. He had fostered the development of a strong Infectious Diseases and Immunization Committee, as an attractive home for subspecialists in this new and rapidly growing area (Victor was one of Canada's first infectious diseases subspecialists). I chaired the committee at the time, and I remember the meeting at which he presented the attractive invitation from Health Canada.
Dr Ron Gold and I were elected as co-Principal Investigators, with other committee members volunteering to serve as site investigators. For the initial pilot study among five sites that started in 1991, the investigators included Dr Scott Halperin (Halifax, Nova Scotia), Dr Pierre Déry (Quebec City, Quebec), Dr Ron Gold (Toronto, Ontario), Dr Barbara Law (Winnipeg, Manitoba) and myself (Vancouver, with the added role of establishing the data centre). Starting on a limited scale proved to be a wise idea because it facilitated fine-tuning of surveillance methodology, communications and distribution of responsibilities among the investigators. The pilot study confirmed an important insight of the planners that surveillance limited to vaccine-related adverse events was not enough to sustain an active network - monitors would burn out searching for relatively rare cases. We convinced Health Canada to include surveillance for selected vaccine-preventable infections, which subsequently proved invaluable for timely program evaluations. In retrospect, striking the right balance among surveillance activities at a modest overall cost was central to the project's success.

After the two-year pilot project passed external review, funding from Health Canada was increased to allow 10 centres to participate in 1993. Selection was based on geographical distribution, local centralization of paediatric beds and availability of a paediatric infectious diseases colleague who was willing to serve as an investigator. Additional centres chosen were St John's (Newfoundland and Labrador), Montreal (Quebec, two sites), Ottawa (Ontario) and Calgary (Alberta) (Table 1). In 1994, Alberta Health chose to fund a centre in Edmonton. The renewed contract with Health Canada in 1999 included funding for Edmonton and allowed the addition of a 12th centre in Saskatoon (Saskatchewan) bringing the network to its present configuration. In aggregate, IMPACT centres receive admissions from every province and territory, and account for over $90 \%$ of the nation's tertiary care paediatric beds. Approximately $50 \%$ of the nation's children live near an IMPACT centre. Recent contract periods have spanned five years, usually ending with external reviews. The coPrincipal Investigators continue to report annually to the CPS Infectious Diseases and Immunization Committee as an oversight body, along with reporting to the sponsoring agency (now the Public Health Agency of Canada [PHAC]).

\section{ACCOMPLISHMENTS OF NOTE}

A remarkable fact is the limited turnover of investigators, most of whom joined in mid-career (Table 1). Except for retirement or relocation, members have been happy to

Correspondence: Dr David Scheifele, Vaccine Evaluation Centre, BC Children's Hospital, Room L427, 4500 Oak Street, Vancouver,

British Columbia V6H 3V4. Fax 604-875-2635, e-mail dscheifele@cw.bc.ca 
stay on. Responsibility for analysis and reporting of data have been shared among the group according to individual interests - a strategy that has kept members engaged. Additional experts have contributed in areas of their special expertise (Table 1). Investigators serve as unpaid volunteers, with rewards limited to publication credits. These have been substantial, although it took several years after start-up to amass sufficient case numbers for publication purposes. To date, there have been 44 peer-reviewed publications and 72 scientific abstract presentations.

It has been reassuring to document the rarity of harm from vaccinations. Despite screening every acute neurological admission at participating hospitals (more than 1500 cases per year), we did not find an instance of acute encephalopathy that was likely caused by pertussis vaccination (2). With the switch from whole cell to acellular pertussis vaccine, reports of febrile seizures and hypotonic episodes declined substantially (3). Measles-containing vaccines occasionally cause acute thrombocytopenia, but the outcome is generally benign (4). Detection of several cases of disseminated bacillus Calmette-Guérin (BCG) vaccine infection contributed to a decision to stop routine use in all Aboriginal communities. Monitors provide vital assistance to the Vaccine Safety Division of the PHAC in their reviews of serious adverse events following immunization to identify any causal association or new risks.

The IMPACT project has spanned the introduction of several new vaccines, including those against Haemophilus influenzae type b. From a prevaccination era total of 485 cases in 1985, centres in 2007 encountered only two cases - a reduction exceeding 99\%. Substantial decreases in case numbers are being seen with pertussis, varicella, pneumococcal and meningococcal group $\mathrm{C}$ infections as the related vaccination programs exert their effects. Pneumococcal surveillance began with industry funding and was included in the PHACfunded activities when the new vaccine was licensed. Meningococcal surveillance is currently industry-funded and noteworthy for being population-based (approximately 50\% of the Canadian population), inclusive of children and adults, and is able to assemble data faster than the federal-provincial system. Influenza admissions surveillance is relatively new, spanning four seasons to date and revealing a substantial illness burden. A case-control subproject seeks to estimate annually the effectiveness of influenza vaccine for preventing hospitalization of young children. Rotavirus admissions are the newest surveillance target, with case documentation extending retrospectively from 2005 to the present. Intussusception surveillance is part of this initiative.

Surveillance methodology evolved significantly this past year, with use of a Web-based reporting platform for influenza cases. This has sped up collation of reports, enabling analysis to begin several months earlier than in past years. More of the reporting will switch to electronic format in the near future.

\section{CONTRIBUTORS TO SUCCESS}

Many factors have contributed to the success of IMPACT (Table 2), some due to good planning and others due to corrective adjustments. After 17 years of fine-tuning, mature
TABLE 1

Centres and investigators participating in the
Immunization Monitoring Program, ACTive

Immunization Mear of initial Current (previous)

\begin{tabular}{|c|c|c|}
\hline City, province & $\begin{array}{l}\text { Year of initial } \\
\text { participation }\end{array}$ & $\begin{array}{l}\text { Current (previous) } \\
\text { investigator; associates }\end{array}$ \\
\hline Vancouver, BC & 1991 & $\begin{array}{l}\text { D Scheifele; J Bettinger, project } \\
\text { epidemiologist (S Wootton) }\end{array}$ \\
\hline Calgary, AB & 1993 & T Jadavji; J Kellner* \\
\hline Edmonton, $A B$ & 1994 & W Vaudry; G Tyrell ${ }^{\dagger}$ \\
\hline Saskatoon, SK & 1999 & B Tan \\
\hline Winnipeg, MB & 1991 & J Embree (B Law); R Tsang ${ }^{\ddagger}$ \\
\hline Toronto, ON & 1991 & $\begin{array}{l}\text { D Tran (R Gold, E Wang, } \\
\text { E Ford-Jones) }\end{array}$ \\
\hline Ottawa, ON & 1993 & $\begin{array}{l}\text { N Le Saux (N MacDonald); } \\
\text { S Whiting }\end{array}$ \\
\hline Montreal $(\mathrm{MCH}), \mathrm{QC}$ & 1993 & D Moore (E Mills) \\
\hline $\begin{array}{l}\text { Montreal (SJ UHC), } \\
\text { QC }\end{array}$ & 1993 & M Lebel \\
\hline Quebec City, QC & 1991 & P Déry; G DeSerres" \\
\hline Halifax, NS & 1991 & S Halperin \\
\hline St John's, NL & 1993 & R Morris \\
\hline
\end{tabular}

${ }^{*}$ Associate member, Pneumococcal surveillance project; ${ }^{\dagger}$ Associate member, Pneumococcal surveillance project (National Centre for Streptococcus); ${ }^{\ddagger}$ Associate member, Meningococcal surveillance project (National Microbiology Laboratory); ${ }^{\S}$ Associate member, Post-immunization neurologic events; "Associate member, Influenza vaccine effectiveness study, pertussis. AB Alberta; BC British Columbia; MB Manitoba; MCH The Montreal Children's Hospital; NL Newfoundland and Labrador; NS Nova Scotia; ON Ontario; QC Quebec; SJ UHC Sainte-Justine University Hospital Centre; SK Saskatchewan

efficiency exists. Key contributors to success were the willingness of the federal government (now the PHAC) to partner with the CPS in this project and the investigators' unfailing compliance with project requirements, which add substantial value to the PHAC's surveillance activities. The seed for the IMPACT project fell on fertile soil 18 years previously because the CPS Infectious Diseases and Immunization Committee existed and its members were well-acquainted and trusting of one another. That the initial trust and goodwill extend to the present is a distinctively Canadian personality phenomenon, too seldom articulated but wonderful to have experienced. Canada was also the right size for a cost-efficient network, needing only to span a dozen centres to capture over $90 \%$ of tertiary care paediatric beds, most with free-standing children's hospitals that are easily monitored. An equivalent network for adult hospitals would be desirable but the logistical challenges are much greater, even in Canada.

We were pleased to assist investigators in New Zealand in setting up a paediatric vaccine safety and preventable infections network similar to IMPACT, which was linked to their vaccination program against serogroup B meningococci (5). Investigators with the Australian Paediatric Surveillance Unit modelled their surveillance of severe influenza infections on the IMPACT methodology (6). A surveillance system based in children's hospitals has been considered in the United States (7), with input from IMPACT members, but the large size of the country has favoured development of several separate networks for preventable disease and vaccine safety surveillance. 


\section{TABLE 2}

\section{Contributors to the success of the Canadian Immunization Monitoring Program, ACTive}

- A nucleus of like-minded, committed investigators who knew and trusted one another through service on the Canadian Paediatric Society's (CPS) Infectious Disease and Immunization Committee

- Graduated start-up, beginning with a pilot phase to refine methodology

- Support of the CPS, as a national organization, to promote and administer the project

- Nationwide scope and inclusion of most paediatric tertiary care centres (more than $90 \%$ of such beds)

- Willingness of the federal government (now the Public Health Agency of Canada) to partner with the CPS and provide stable funding in five-year increments, sufficient for the required work

- Periodic external reviews to guide expansion and refine targets of surveillance

- Good balance between vaccine safety and preventable infections targets, making the job of monitors rewarding. Training of monitors to ensure consistency of data and their ongoing support by a monitoring coordinator/trainer/liaison

- Shared leadership and opportunities for investigators to lead publications in areas of interest

- Stable funding of the data centre, including a project epidemiologist to facilitate analyses and enhance the surveillance methodology

- Inclusion of associate investigators to provide specific expertise (Table 1)

- Demonstrated value to sponsor, adding more detailed, faster-assembled data to existing sources

- Recognition of the potential for surveillance assistance in a national emergency, such as an influenza pandemic

- Emphasis on sharing of data through publications, newsletters, Web sites and presentations

- Potential to include industry-funded surveillance targets at reasonable cost in anticipation of new vaccination programs

- Substantial numbers of publications, as the reward for investigator participation

- Funding of annual meetings of the monitors and investigators to promote cohesion, consistency and communication

\section{IMPACT IN PERSPECTIVE}

Disease surveillance is an essential activity to monitor the health of children. Surveillance data support the rationale for new vaccination programs and gauge their subsequent safety and effectiveness. The added value of active surveillance for selected target conditions has been well-demonstrated by the IMPACT project, motivating ongoing funding from the PHAC and confirming the original premise.

The CPS remains the logical host for this project. It provides a workable interface with government sponsors,

\section{REFERENCES}

1. Scheifele DW, Halperin SA; members of the Canadian Paediatric Society/Health Canada Immunization Monitoring Program Active (IMPACT). Immunization Monitoring Program, ACTive: A model of active surveillance of vaccine safety. Semin Pediatr Infect Dis 2003;14:213-9.

2. Moore DL, Le Saux N, Scheifele D, Halperin SA; Members of the Canadian Paediatric Society/Health Canada Immunization Monitoring Program, ACTive (IMPACT). Lack of evidence of encephalopathy related to pertussis vaccine: Active surveillance by IMPACT, Canada, 1993-2002. Pediatr Infect Dis J 2004;23:568-71.

3. Le Saux N, Barrowman NJ, Moore DL, Whiting S, Scheifele D, Halperin S; members of the Canadian Paediatric Society/Health Canada Immunization Monitoring Program, ACTive (IMPACT). Decrease in hospital admissions for febrile seizures and reports of hypotonic-hyporesponsive episodes presenting to hospital emergency departments since switching to acellular pertussis effective financial administration across 12 centres and valuable communication paths to paediatricians and the public. The CPS Infectious Diseases and Immunization Committee provides useful oversight and continues to knit subspecialists together.

I am confident that IMPACT will continue to flourish, and I encourage those in other subspecialties to consider networking in a similar fashion. Developing and participating in strong subspecialty committees is the ideal beginning, with our identified contributors to success (Table 2) providing guidance on the way forward.

vaccine in Canada: A report from IMPACT. Pediatrics 2003;112:e348-53.

4. Jadavji T, Scheifele D, Halperin S; other members of the Canadian Paediatric Society/Health Canada Immunization Monitoring Program, ACTive (IMPACT). Thrombocytopenia after immunization of Canadian children, 1992 to 2001. Pediatr Infect Dis J 2003;22:119-22.

5. McNicholas A, Galloway Y, Stehr-Green P, et al. Post-marketing safety monitoring of a new group B meningococcal vaccine in New Zealand, 2004-2006. Human Vaccines 2007;3:196-204.

6. Zurynski YA, Lester-Smith D, Festa MS, Kesson AM, Booy R, Elliott EJ. Enhanced surveillance for serious complications of influenza in children: Role of the Australian Paediatric Surveillance Unit. Commun Dis Intelligence 2008;32:71-6.

7. Fine AM, Goldmann DA, Forbes PW, Harris SK, Mandl KD. Incorporating vaccine-preventable disease surveillance into the National Health Information Network: Leveraging children's hospitals. Pediatrics 2006;118:1431-8.

All Canadian Paediatric Society position statements/notes are reviewed, revised or retired as needed on a regular basis. For the current version, please consult the "Position Statements" section of the CPS website (www.cps.ca/english/publications/statementsindex.htm).

This article also appears in the January 2009 issue of Paediatrics $\mathcal{E}$ Child Health. 


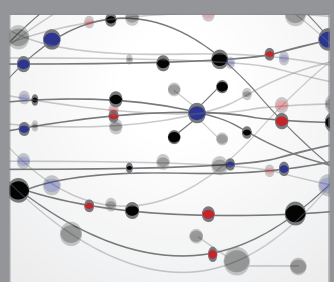

The Scientific World Journal
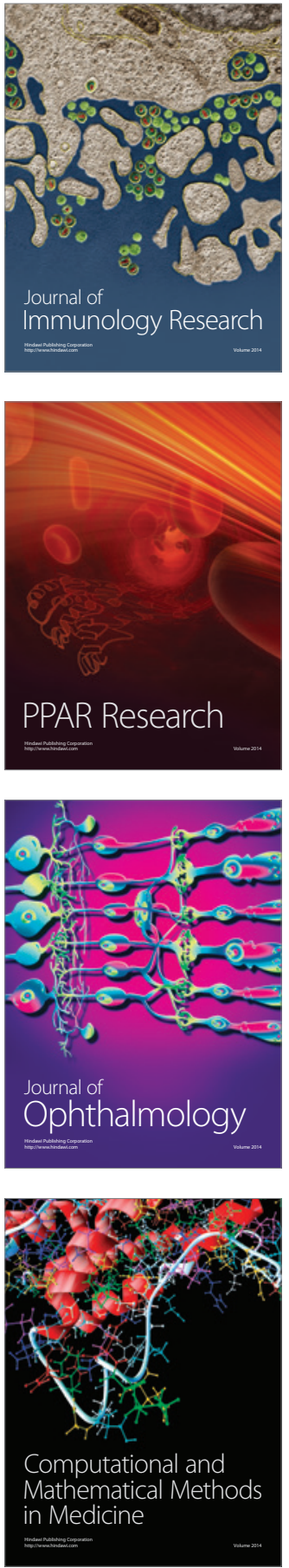

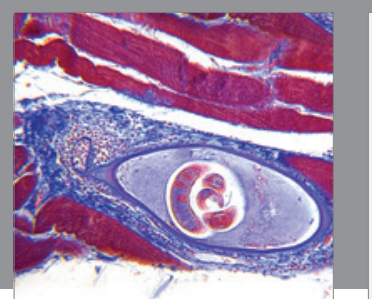

Gastroenterology Research and Practice

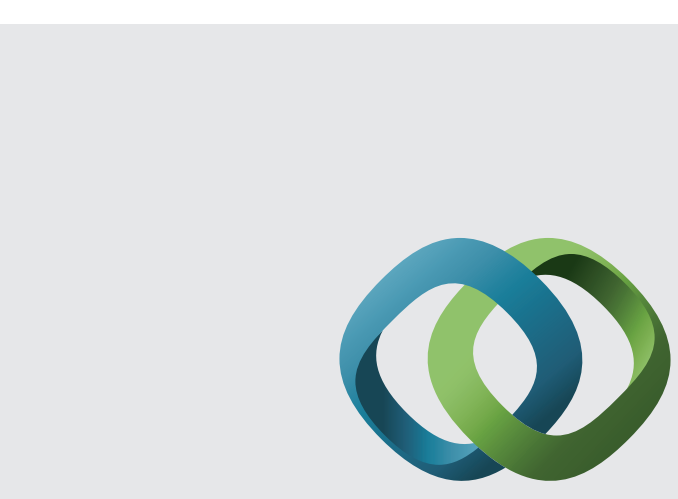

\section{Hindawi}

Submit your manuscripts at

http://www.hindawi.com
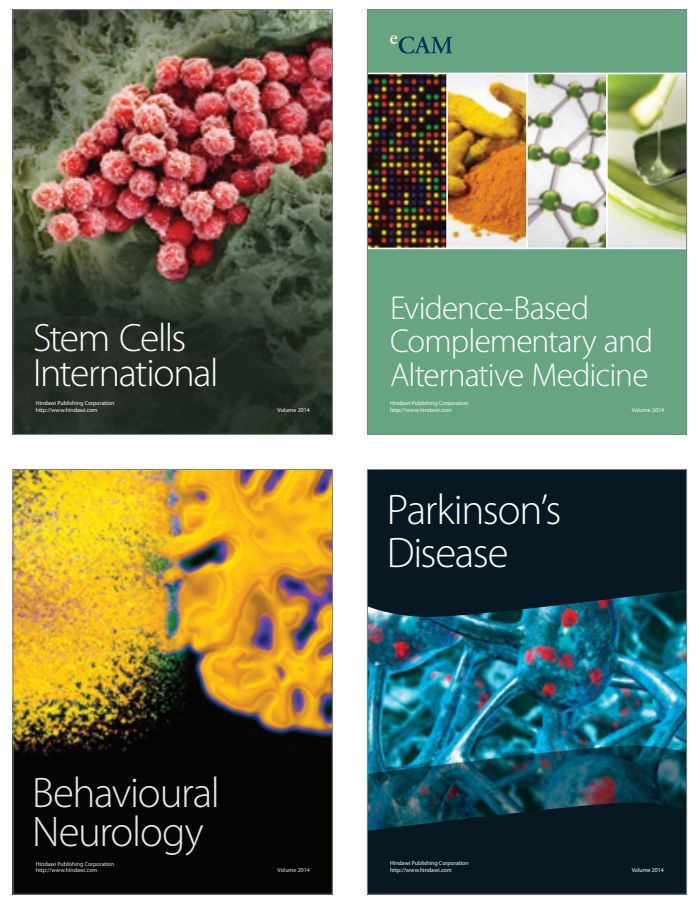
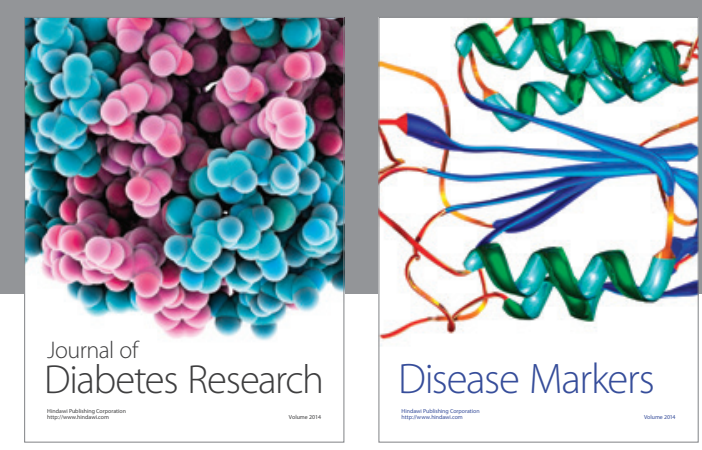

Disease Markers
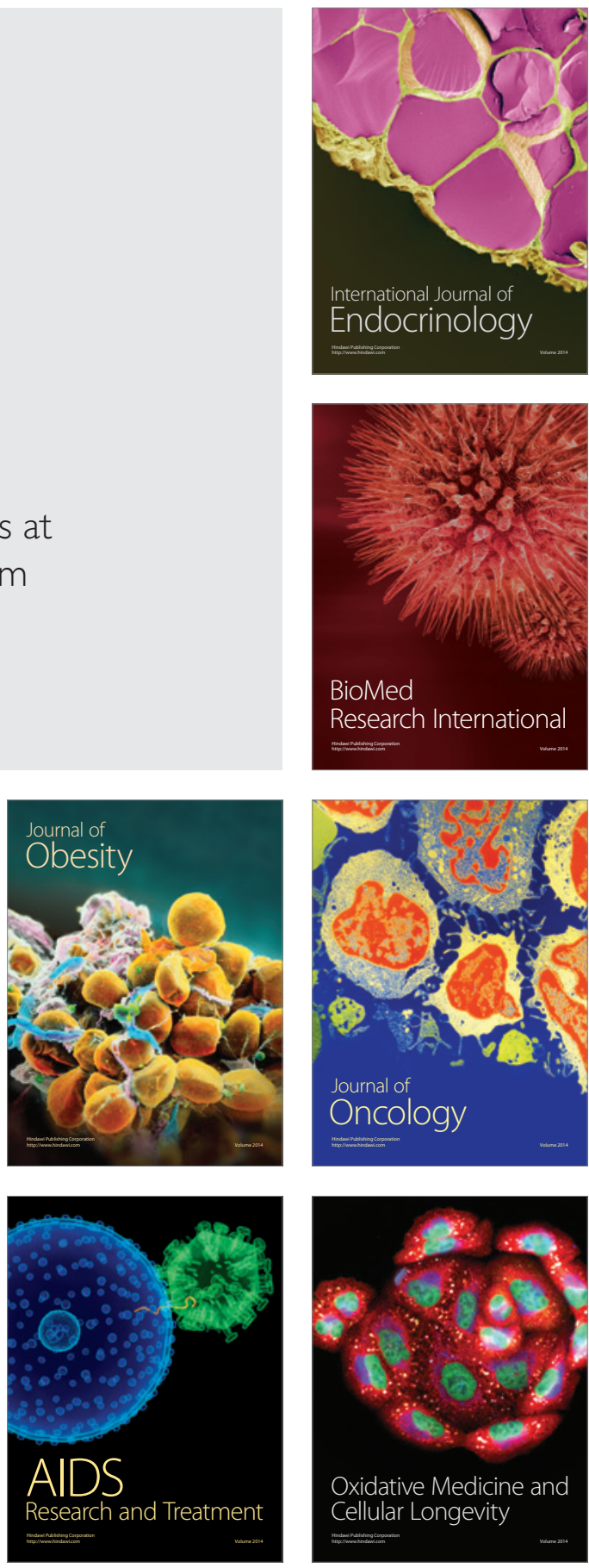